\title{
LOS ECOS DEL TESORO DE ALISEDA EN LAS DAMAS Y EN LAS OFERENTES IBÉRICAS
}

\section{ECHOES OF THE TREASURE OF ALISEDA ON IBERIAN LADIES AND WORSHIPERS}

\author{
Carmen ARANEGUI GASCÓ \\ Universidad de Valencia
}

Recordando a Mila Gil-Mascarell Boscà (1941-1994).

\section{Resumen}

Este artículo considera el Tesoro de Aliseda como la primera ostentación conjunta masculina y femenina de la península ibérica. Plantea la relación de la orfebrería extremeña con la ibérica. Ambas comparten tipologías hasta el siglo IV a.C. y la diadema frontal se proyecta varios siglos más, como uno de los signos de prestigio femenino ibérico, presente en las esculturas hasta la época de la romanización.

Palabras clave: Orfebrería extremeña. Orfebrería ibérica. Escultura femenina ibérica. Santuario del Cerro de los Santos.

\footnotetext{
Abstract

This paper regards the Treasure of Aliseda as the first joint display of male and female wealth in the Iberian Peninsula. It raises the influence between goldsmithing from Extremadura on Iberian jewelry. Both shared typologies until the $4^{\text {th }}$ century BC and the frontal diadem endures for centuries as one of the Iberian signs of feminine prestige visible in worshiper' sculptures dating until Romanization period.

Key words: Ancient Goldsmithing. Iberian Sculptures of Women. Sanctuary of Cerro de los Santos.
} 
Al cumplirse un siglo del hallazgo casual del Tesoro de Aliseda (Cáceres) la reflexión sobre el eco de las joyas que lo componen en los aderezos femeninos ibéricos plantea una cuestión tan compleja como la del propio tesoro. Los excelentes estudios realizados desde la Universidad de Extremadura comenzaron por ampliar el foco de la investigación hacia el paisaje de la divisoria de aguas donde se localiza Aliseda, después han situado el hecho en relación con los enclaves protohistóricos de la Sierra del Aljibe, con la mina Pastora y, en concreto, con la "casa-santuario" que está a sus pies, en el área de Las Cortinas, y finalmente han dado a conocer la heterogeneidad técnica y cronológica de las orfebrerías analizadas, todo ello en el periodo Orientalizante, entendido en un sentido amplio, entre los siglos VII-VI y V-IV a.C. (Rodríguez Díaz et al., 2019). Debido a estos conocimientos, el ambiente cultural del depósito áureo ha dejado definitivamente de entenderse como funerario para asociarse a un ritual público de fundación de un linaje, celebrado al inicio de la primavera, según sugiere tanto la confluencia de joyas masculinas y femeninas como la orientación de la estructura principal de la "casa-santuario" hacia el orto heliaco de la estrella Arturo, previo al equinoccio. En estos términos, esta ocultación constituye un caso distinto al de los escondrijos de platero propios de situaciones políticamente inestables. También difiere por su cronología y heterogeneidad de la ofrenda votiva del Tesoro del Carambolo (Camas) (Belén, 2009: 193-228) y, como se ha dicho, de los ajuares funerarios con amortización de joyas, que tienen ejemplos, muy modestos comparativamente, en el área de estudio (Celestino, 2000; Almagro Gorbea, 2008: 371-400; Belén, 2012: 179-200), relativamente rica en hallazgos aislados de placas de oro trabajadas hasta la Segunda Edad del Hierro (Berrocal, 1989: 279-291). De este modo, la nueva interpretación de Aliseda discurre desde una orfebrería con precedentes y paralelos hacia un ritual de legitimación mediante la ofrenda de oro, plata y objetos valiosos en un espacio residencial y sagrado, sin precedentes claros, pero tal vez enlazado con la autoridad de los santuarios fenicios para transferir identidad a un colectivo (Machuca, 2017), aunque con la peculiaridad de la conjunción simbólica de ambos sexos expresada en las joyas.

El lenguaje arqueológico no es verbal. En primera instancia, el significado explícito de una pieza se deduce de su materia, de su tecnología y de su función, a partir de las que la investigación prosigue hasta encontrar el significado implícito que la inserta en la sociedad a la que perteneció y por la que fue utilizada en prácticas no siempre claras para su estudio. Con escasos argumentos contrastados etnográficamente, el estereotipo más común para la protohistoria otorga categoría de tesoro al bronce, plata y oro como sinónimos de una ostentación selectiva que resulta difícil asignar a un estatus determinado antes de que los ítems valiosos se estandaricen para ser entendidos culturalmente, bien como riqueza, o bien como signos de poder privativos de un grupo social. $\mathrm{Y}$ como la 
opción, ya sea materializada o bien representada iconográficamente, no siempre es evidente, solo la contextualización autoriza a reconocer una vajilla, fíbula, brazalete, broche de cinturón, arma, diadema, unas arracadas, un collar, el marfil... como distintivo jerárquico, con un valor u otro a partir de la cantidad y de la calidad. El simposio participado por notables enriquecidos se deduce del oro y de las tipologías del Bronce Tardío en el Tesoro de Villena (Hernández, 2017: 37-60), mientras que el del Carambolo (siglo VI a.C.) se considera un extraordinario don litúrgico depositado en un santuario fenicio por alguien (fenicio) investido con la autoridad que le confieren los sellos acreditativos que ofrece (Escacena y Amores, 2011: 107-141; Navarro y San Martín, 2018: 157-181). Únicamente el encuadre cultural y la iconografía clarifican el sexo de un tesoro. Aun sin iconografía antropomorfa asociada, los dos últimos mencionados parecen exclusivamente masculinos por sus formas y función.

El acceso de ambos sexos a valores exclusivos de la cúpula social tiene el interés de mostrar el capítulo de la ostentación conjunta en masculino y en femenino, implícito en sociedades estructuradas peninsulares del primer milenio antes de la era que ya no entienden la fuerza sin la tradición. Por eso es conveniente sustentar este capítulo con una argumentación sólida. Hacia 1960 las prolijas estelas diademadas fueron identificadas como imágenes femeninas paralelas, para algunos autores, a las estelas de guerrero del oeste peninsular (Celestino, 2001), aunque la verificación del halo arqueado como una joya y del sexo del ser humano que lo ostenta como una mujer esté plagada de incógnitas y ni una sola diadema haya sido encontrada en lugares relacionados con dichas estelas (Santos, 2009: 27). Esta carencia se resolvió indicando que una representación puede mostrar lo que no se posee, pero no se explicó en qué casos.... Así que tal respuesta anima a mejorar la narrativa sobre la convergencia de géneros por parte de arqueólogas y arqueólogos, para no forzar la amplitud cronológica del fenómeno ni, sobre todo, desplazar siempre lo femenino hacia lo que no se posee.

Al margen de las estelas, la época de Aliseda apenas cuenta con imágenes antropomorfas autóctonas y los bronces fenicios de su entorno, así como los escasos sarcófagos antropoides, no incluyen joyas en su canon representativo, aunque las depositan en los enterramientos (Perea, 2000: 281-292; Martín y Fernández, 2007: 187-194; García Gandía, 2009). Son tiempos en los que las necrópolis orientalizantes empiezan a dar un porcentaje de tumbas femeninas, irregular pero estable, superior al tercio de las que tienen identificado el sexo de los difuntos, cifra sintomática de la proporción de mujeres dignas de compartir un lugar de memoria. Prosiguen en tal etapa las deposiciones dobles de un hombre y una mujer con ajuares ricos, hipotéticamente en La Joya (Huelva), y con seguridad en Medellín, Acebuchal y Cruz del Negro (ambas en Carmona), La Mesa de Setefilla (Lora del Río), Porcuna, Baria (Villaricos), Les Casetes 
y Poble Nou (ambas en Villajoyosa)..., acompañadas, principalmente, de ofrendas de bronce (Campos, 2019: 46-57) que repiten el pebetero, la bandeja de asas y, en menor medida, el jarro, junto a algún objeto de marfil y collares de oro con cuentas de piedras duras o pasta vítrea, escarabeos y pequeños colgantes de tipología púnica (Quillard, 2013), sin adscripción de género. De tal estado de la cuestión se desprende que el conjunto de Aliseda es el primero y el único en la península ibérica que asocia masculino y femenino con un mismo índice de ostentación: el oro.

El arte nutre el imaginario colectivo con códigos visualizables, distintos a los textos escritos, dignos de ser interpretados a través de una metodología específica a la que hay que atenerse para que la plástica constituya una fuente autónoma para la historia (Torelli, 1997: 192). El lugar, el tamaño, la calidad... modifican la jerarquía de un objeto y ayudan a deducir el encuadre de género (Frontisi-Ducroix y Lissarrague, 1998: 137-143).

Estas son, en síntesis, las líneas generales previas a las damas representadas en la escultura ibérica. En las páginas que siguen prestaré atención a estos factores y dejaré en segundo plano el estilo, ya que la escultura ibérica carece de una teoría estética que regule su desarrollo, en el que autores coetáneos muestran un conocimiento del oficio desigual. Por ello me atendré a los sistemas de imágenes, que las relacionan con argumentos no estéticos, con el fin de esbozar un encuadre social que precise cuándo y por quién fueron utilizadas las joyas como construcciones culturales (Renfrew y Morley, 2007).

\section{JOYAS IBÉRICAS. HALLAZGOS E IDEALIZACIÓN}

\subsection{LAS JOYAS DE LAS DAMAS}

Hace un siglo Aliseda tuvo en el Tesoro de Jávea su referente, en un momento en que la fachada mediterránea se consideraba culturalmente más avanzada que la vertiente atlántica gracias al buen estado de conservación del busto de Elche y de la diadema de Jávea (Fig. 1A), descubiertos en 1897 y 1904 y famosos internacionalmente (Huezey, 1897: 505-509; Paris, 1906: 424-435). Iberia era, así, un todo civilizado por Grecia. Sin embargo, hallazgos casuales, excavaciones más recientes en la vertiente atlántica (Celestino y Jiménez Ávila, 2005) y estudios sobre orfebrería peninsular (Nicolini, 1990; Perea, 2018: 357-368) han instituido un panorama dual, atlántico y mediterráneo, dando a conocer que las ondas del eco de Aliseda tardaron alrededor de un siglo en llegar a la tierra de las damas ibéricas, situada entre el río Júcar, la alta Andalucía y el Mediterráneo (Aranegui, 2012: 260-265). 
Sucede, por consiguiente, que las piezas de taller gaditano o importadas, como el cinturón áureo, los sellos basculantes y el extraordinario escarabeo de esteatita (Nicolini, 1990: lám. 95), no tienen derivados en el área de las damas, mientras que algunas tipologías atribuidas al taller extremeño, principalmente la diadema, tienen continuidad en Jávea, aunque ejecutada por un exclusivo orfebre que pone una tecnología griega o magno-griega (Perea, 1996: 102-104) al servicio de alguien que conoce perfectamente el tipo que le corresponde y lo asocia al brazalete argénteo en espiral, ibérico en este contexto.

Desde el inicio del siglo V a.C. la sociedad ibérica del sur ${ }^{1}$ introduce la escultura en necrópolis de incineración, monumentalizadas antes y con más grandeza que los santuarios o los oppida, en las que también hay deposiciones dobles hombre-mujer. Esta es su manera de exhibir una identidad que proviene de sus antepasados (Perea, 2006: 49-68; Wulff, 2009: 11-50). Además de tumbas, algunas necrópolis muestran no solo esculturas aisladas de caliza a escala natural sino también escenificaciones con personajes en movimiento que las convierten en genuinos espectáculos públicos. Los mejores ejemplos residen en el amplio muestrario de la fase oretana del Cerrillo Blanco de Porcuna (González, 1987) y en restos aislados contestanos de La Alcudia de Elche (Aranegui, 2018: 112-117) que, además del repertorio zoomorfo, introducen una iconografia masculina y femenina inédita como tal en el Orientalizante peninsular, pero implícita en las joyas de Aliseda. Los heroicos personajes esculpidos dan la primera versión de la jefatura ibérica, exhiben su alto rango a través de su indumentaria, armamento y ornato, del que el brazalete en espiral masculino es la joya que primero se manifiesta, seguida por el torques (Fig. 1B). Pero estas imágenes fueron destruidas por rivalidades internas al poco de su instalación: los rostros humanos de casi todas ellas desaparecieron. No se sabe, por tanto, si las mujeres estantes portaban tocados o arracadas, por ejemplo, pero es seguro que no llevan collares sobre su torso, que se conserva; una mujer del Cerrillo Blanco (h: $0,87 \mathrm{~m}$ ), por ejemplo, muestra una serpiente que asoma desde su hombro, tal vez asociada a una divinidad propia de la que pudiera ser mediadora, pero el ornato correspondiente a una dama sedente se desconoce, ya que solo consta un fragmento de su parte inferior (González, 1987, núms. 17 y 37).

Es en el tránsito al siglo IV a.C. cuando se difunde en algunas de estas necrópolis una imagen femenina en gran formato colmada de joyas ${ }^{2}$. Entronizada o sedente, en

\footnotetext{
${ }^{1}$ El río Júcar marca la divisoria entre el área ibérica central y los iberos del sur, protagonistas de este texto.

${ }^{2}$ En el siglo IV a.C. las damas entronizadas han sido halladas, casi siempre casualmente, en las necrópolis de La Alcudia de Elche, Benimassot (Alicante), Caudete (Albacete), Llano de la Consolación (Montealegre del Castillo), El Cigarralejo (Mula), Cerro del Santuario (Baza), Cerrillo Blanco (Porcuna). Los bustos proceden de La Alcudia de Elche y de Cabezo Lucero (Guardamar).
} 

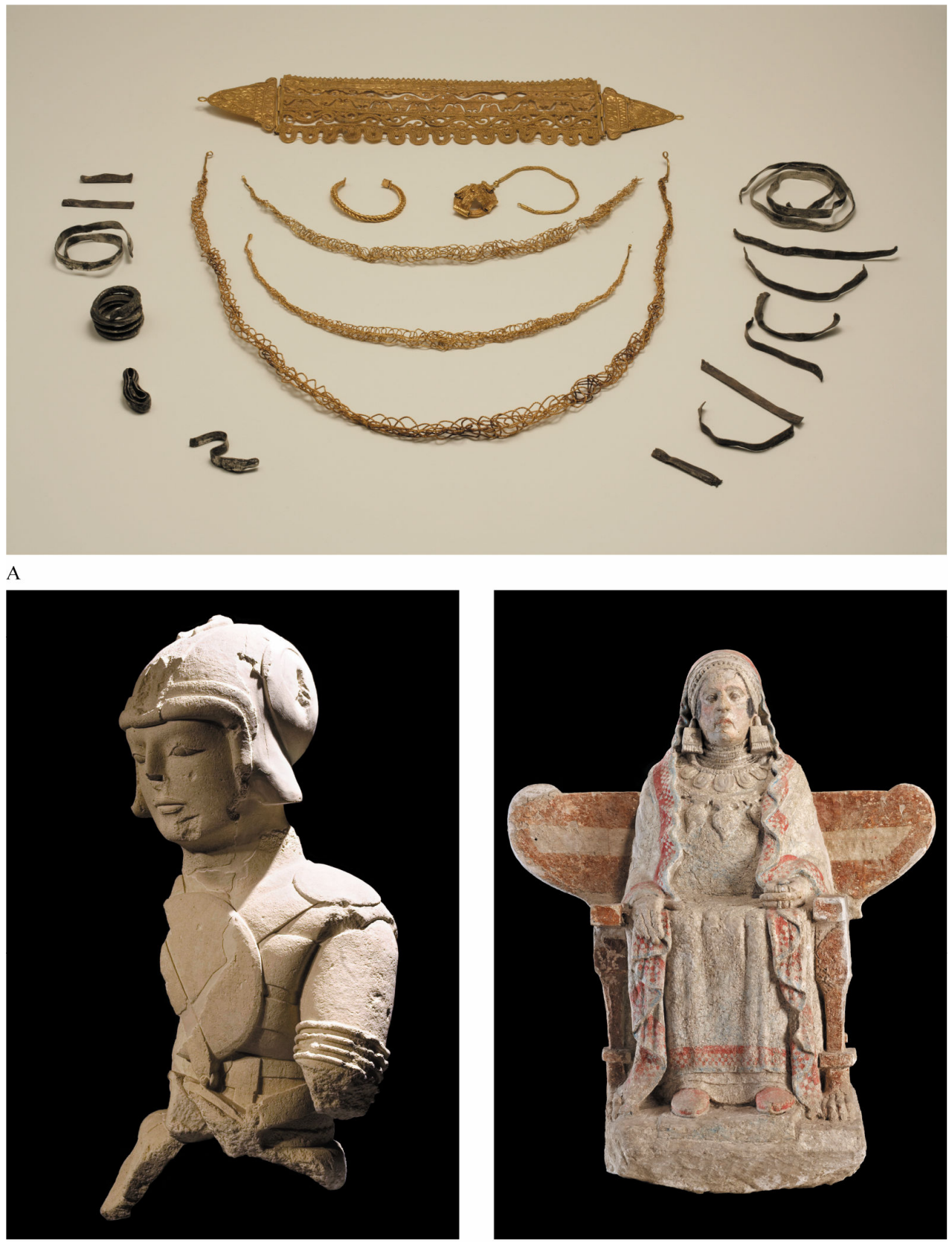

B

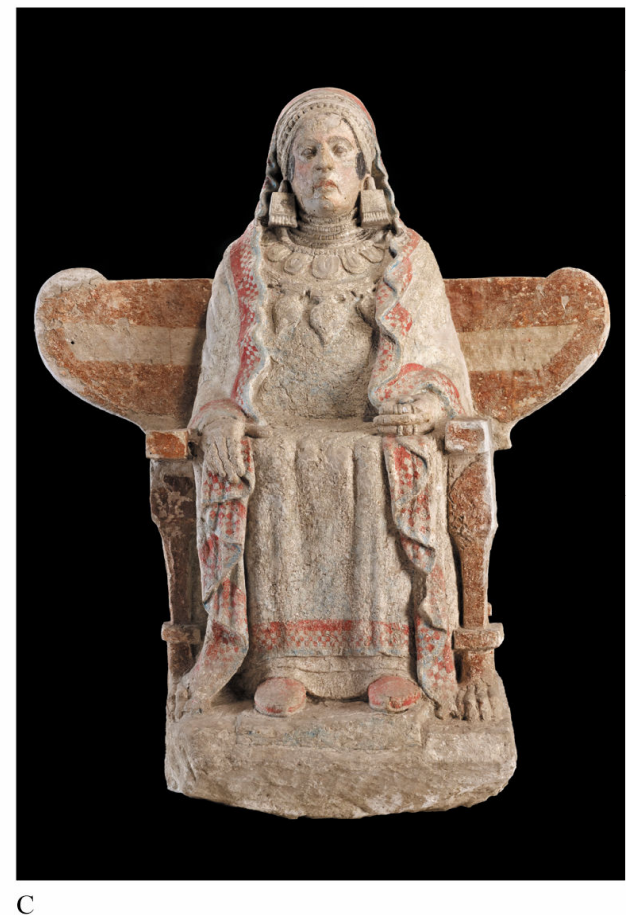

Figura 1. A) El Tesoro de Jávea, s. IV a.C., joyas de oro y plata (MAN); B) El Guerrero del Cerrillo Blanco, s. V a.C., con brazalete en espiral (Museo de Jaén); C) La Dama de Baza, s. IV a.C. (MAN). 
posición hierática y frontal, vestida con túnicas prendidas con fíbula anular, cubierta con cofia, velo y manto, calzada, con diadema sobre la frente, el cabello recogido en rodetes adornados a la altura de las orejas, con pendientes, tres collares con grandes colgantes sobre el busto, pulseras y sortijas (Fig. 1C) (Perea, 2006: 49-68), es la primera idealización en femenino de la potestad ibérica, que recibió el nombre de dama cuando ingresó el busto de Elche en el Louvre (París).

En efecto, en un segundo momento y solo en el entorno de Ilici (La Alcudia de Elche), la dama se sintetiza en un busto largo como los de terracota del Mediterráneo helenístico (Kassab et al., 1985: 77-114). Es muy probable que esta tipología básica llegara a la Contestania desde la coroplastia del Puig des Molins (Ibiza) (San Nicolás, 1987), crisol de culturas a este efecto en el siglo IV a.C., aunque en el medio ibérico las damas-busto entran en la categoría de la escultura de piedra, que las distinguen de millares de terracotas femeninas de distintos tamaños que circulan por el Mediterráneo coetáneamente, adornadas con sencillos aros de oro y collares en los ambientes púnicos. Los dos bustos ibéricos conocidos muestran esculpida, por su parte, la orfebrería de alta calidad de las damas sedentes.

Los tejidos coloreados, la ocultación del cabello y determinadas joyas constituyen un léxico creado para las damas. El lino se reconoce en sus túnicas, cofia y velo; la lana, en su generoso manto. En cuanto a alhajas, la diadema cubre siempre el nacimiento frontal de su cabello, los rodetes y pendientes fluyen a ambos lados de sus mejillas, para encuadrar su mirada, y el busto, a la manera de los pectorales de Akragas (Agrigento) (Albertocchi, 2004), soporta tres collares de cuentas agallonadas o esféricas, como las de pasta vítrea o piedras duras, en sartas de las que penden colgantes de oro o plata, de los que bullae (porta-amuletos) y anforiscos aumentan su tamaño con respecto a las piezas reales para lanzar un mensaje al espectador, utilizando una distorsión característica del arte ibérico (Fig. 2A) (Aranegui, 2018: 97).

Las aristocracias recogen el eco de Aliseda para que se sigan produciendo joyas en el área ibérica, pues la tumba 100 de Cabezo Lucero (Guardamar del Segura), de mediados del siglo IV a.C. (Uroz, 2006), ha dado a conocer el mejor conjunto de instrumentos y matrices de orfebre de la península (Perea y Armbruster, 2011: 158171), indicio de un taller contestano. Los porta-amuletos, en consecuencia, adquieren significado propio como alternativa a los colgantes púnicos de pasta vítrea o hueso, aunque tipológicamente provengan del mundo clásico. Diademas y collares se complementan con pulseras y sortijas, visibles en los dedos de la Dama de Baza, signo este que confiere la autoridad de sellar o certificar (Perea y Olmos, 2018: 535-566). Con todo, en este caso, por encima de los atributos de la representación esculpida, 


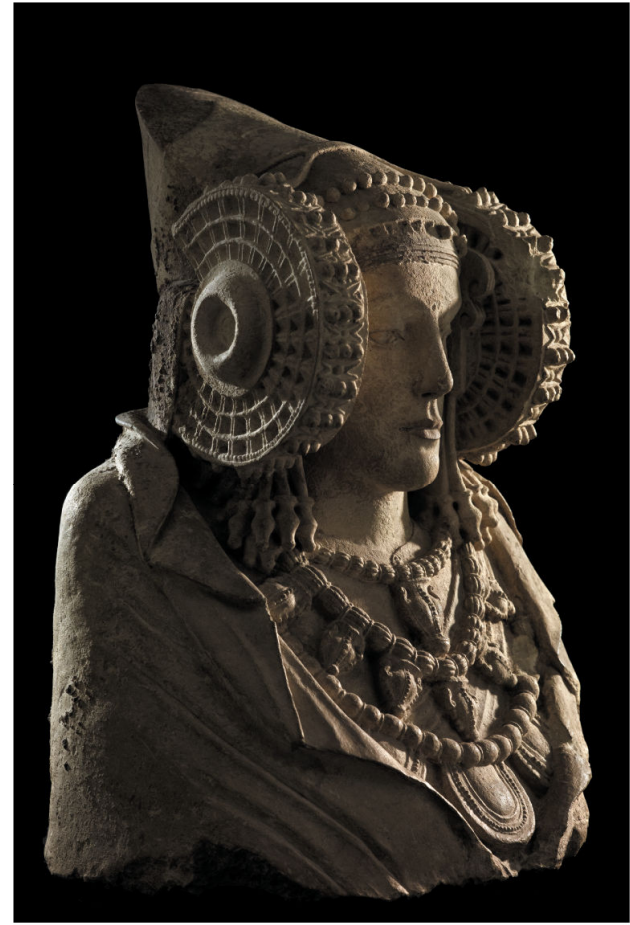

A

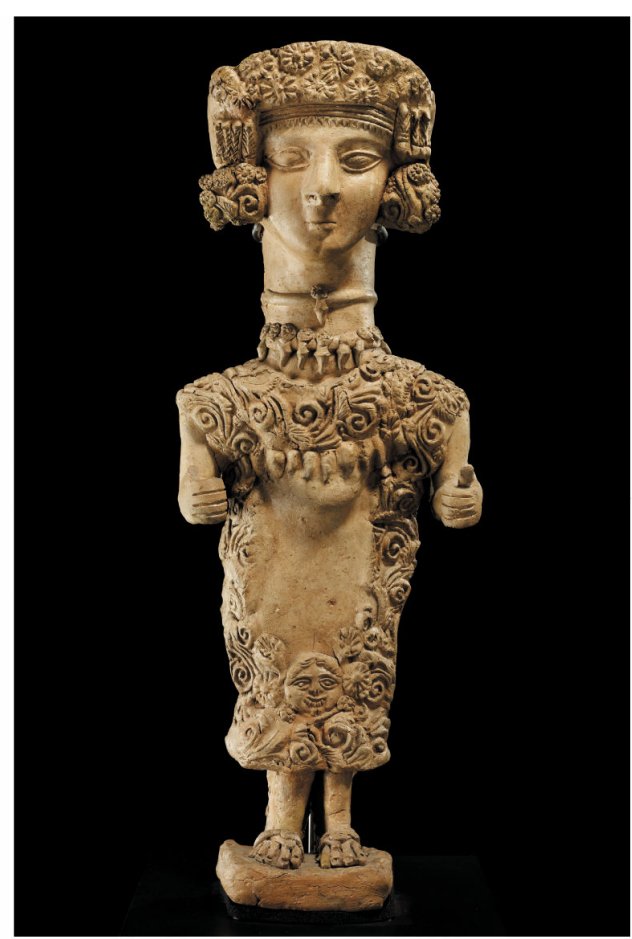

B

Figura 2. A) Busto de la Dama de Elche, s. IV a. C. (MAN); B) La dama de Ibiza, s. III a.C. (Museo del Puig des Molins, Ibiza, expuesta en el MAN).

son las ofrendas de panoplia en su hipogeo número 155 las que aseguran que en El Cerro del Santuario (Baza) fue sepultada una mujer muy poderosa en el interior de una escultura de significado étnico.

Un semblante femenino adulto enmarcado por rodetes, con diadema y tres ricos collares eco de Aliseda, cobra peso en el imaginario ibérico. Es una personificación con matices regionales, como los grandes pendientes en forma de cestillo o celemín de tipología púnica de la Dama de Baza (Almagro Gorbea, M. ${ }^{a}$ J., 1989-90: 118), que el escultor destaca por encima de sus pequeños rodetes pintados de negro para indicar su arraigo en el sur (Aranegui, 2010: 185-194). Se trata de un código que se desconocería de no ser por las esculturas (Aranegui, 2008: 205-224).

Por todo lo expuesto, actitud, vestimenta y alhajas constituyen el más alto canon semántico femenino ibérico: el de la dama, término que no tiene equivalente en otras imágenes de distintas culturas peninsulares coetáneas. Diversos autores contemporáneos, sin embargo, lo siguen aplicando a hallazgos menores de Cádiz o Villaricos e 
incluso nombran dama tanto a una importación de alabastro en forma de vaso de perfumes de Tutugi (Galera) (h: 18,5 cm) (Torres, 2011: 49-56 y 273-278; Rodríguez Ariza et al., 2008: 169-180), como al pequeño exvoto de caliza de Torrepardones (Baena) (Marín y Belén, 2002-03: 177-194), ninguno de los cuales, ni por su iconografía ni por su formato, tienen que ver con la dama emblemática del Ibérico Pleno, propia de un sistema de imágenes que exhibió, a escala natural casi siempre, la tradición y la riqueza en femenino y la valentía y la fuerza en masculino para inculcar a los vivos desde necrópolis monumentales sus valores ancestrales, de los que guardó consciencia (Izquierdo, 1998: 185-193).

Un caso distinto es el de la terracota del Puig des Molins, conocida como dama (MAN 1923/60/541, h.: 45,5 cm), tipo que cuenta con otros derivados ebusitanos. Estante, en actitud orante, esta versión reinterpreta el canon ibérico con la diadema, los rodetes y los tres collares con colgantes característicos, pero es ebusitana por ir vestida con una túnica fantasiosa y calzada con sandalias, que le dan el toque local (Fig. 2B), diferente al de los bustos mayoritarios en aquella necrópolis. Es, positivamente, una representación híbrida.

\subsection{LOS SANTUARIOS: JOYAS OFRECIDAS Y JOYAS REPRESENTADAS}

Del 300 a.C. en adelante los enterramientos monumentales van decayendo como hitos de ostentación y son los santuarios los que consagran el lugar en el que la sociedad ibérica se reconoce como un todo depositando exvotos que atestiguan ritos de paso, en un paisaje nuevo que se abre hacia rutas inter-territoriales. En este contexto se presenta el primer conjunto ibérico de joyas femeninas y masculinas, hallado dentro de una vasija en Jávea, junto a Dianium (Denia), a pocos kilómetros del Pic de l'Àguila, probable emplazamiento de un santuario litoral atribuido por los textos a Ártemis (Str. III, 4, 6-8) (Aranegui, 2015: 158-176). Allí también han sido recuperados, en buen estado, tres torques ligeros con bucle central y un colgante, masculino por su iconografía, metáfora de la fecundidad, todo de oro en este último depósito (Perea, 2006: 57-59).

El Tesoro de Jávea (Fig. 1) se compone de ocho piezas frente a las veintitrés de Aliseda. Ya no contiene apliques para la indumentaria, salvo la fíbula, ni servicio de libación, ni espejo, ni arracadas, ni brazaletes calados, ni sortijas, ni pedrería, pero mantiene completa la tipología de la diadema de extremos triangulares, realizada aquí con una exquisita tecnología helenística, más una pulsera, tres collares simples de alambre trenzado y una fíbula con cadena, todo ello de oro, del lado femenino, así como un brazalete enrollado en espiral rematado por cabezas de serpiente y unas tiras 
de plata, típicamente ibéricos, supuestamente del masculino (Aranegui, 1996: 97-121). El conjunto muestra la convergencia de ambos sexos en un entorno sacro, como en Aliseda, pero articula el oro en femenino y la plata en masculino, como sucede en otros hallazgos ibéricos.

Los collares sencillos que en número de tres (Perea, 1997: 145-157) se suman a las diademas en este y otros casos, no tienen que ver más que por su número con los de las damas funerarias porque no tienen colgantes grandes, lo que rebaja el nivel social de la mayoría de las oferentes juveniles que los muestran.

Hacia el norte, sin embargo, las tipologías del collar y de la diadema se pierden. Pero en la provincia de Castellón, la combinación de joyas de oro y plata aparece en el depósito ritual del Puig de la Nau (Benicarló), de finales del siglo V a.C., si bien consta solamente de dos pares de arracadas de oro femeninas y un pasador, más la reiterada pulsera helicoidal de plata, muchas veces masculina (Oliver y Perea, 1999: 198-208).

Dejando al margen de los ecos de Aliseda las joyas plasmadas en quema-perfumes y otras terracotas de depósitos votivos debidos a la interacción greco-púnica (Mas Castellar en Pontós, Bordisal en Camarles, Cova de les Encantades en Cabrera de Mar, etc.) (Horn, 2011), la cultura ibérica practica una ritualidad sin imágenes en la mitad septentrional de su territorio, con cuevas-santuario sin exvotos-tipo antropomorfos ni joyas, salvo excepciones. Pero desde el área central hacia el sur, con distintos matices, modelos y rutinas (Rísquez y Rueda, 2013), desde el siglo III al II a.C., la ritualidad se hace visible fuera de los espacios privados e incluso extramuros, a la vez que reduce la ofrenda de oro y plata a escasas laminillas decoradas con una imagen incisa, por ejemplo en Collado de los Jardines (Castellar de Santisteban) y en La Encarnación (Caravaca de la Cruz), y se puebla de exvotos figurativos de arte menor y tamaño muy reducido (h: 7 a $14 \mathrm{~cm}$ ), exceptuando El Cerro de los Santos (Montealegre del Castillo). En comparación con los antecedentes funerarios, los santuarios suponen un programa de ostentación modesto, que se expresa con un lenguaje en el que aumenta desmesuradamente la proporción de representaciones humanas con respecto a las zoomorfas, con el propósito de identificar genéricamente a quienes reiteran periódicamente su identidad en un lugar sagrado a lo largo de su vida, expresándose con un lenguaje corporal y gestual desconocido en las necrópolis (Izquierdo, 2008: 251-296). En general, se trata de estatuillas erguidas y descalzas de bronce, de terracota o de caliza, asequibles a un sector amplio de la sociedad, por lo que se cuentan por miles, aunque solo unas pocas recuerdan todavía el eco de Aliseda, heredado de la escultura funeraria. 


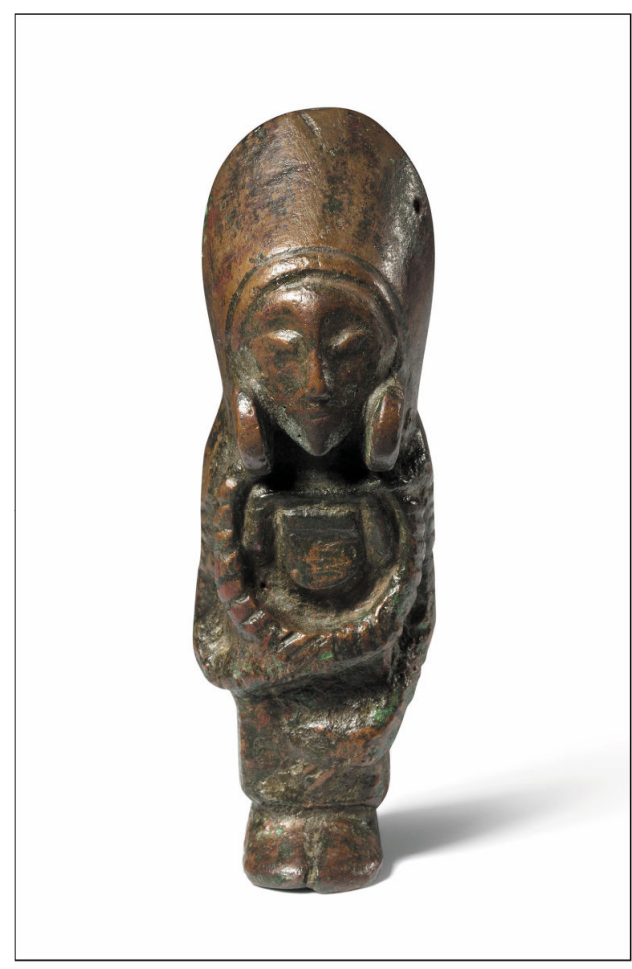

A

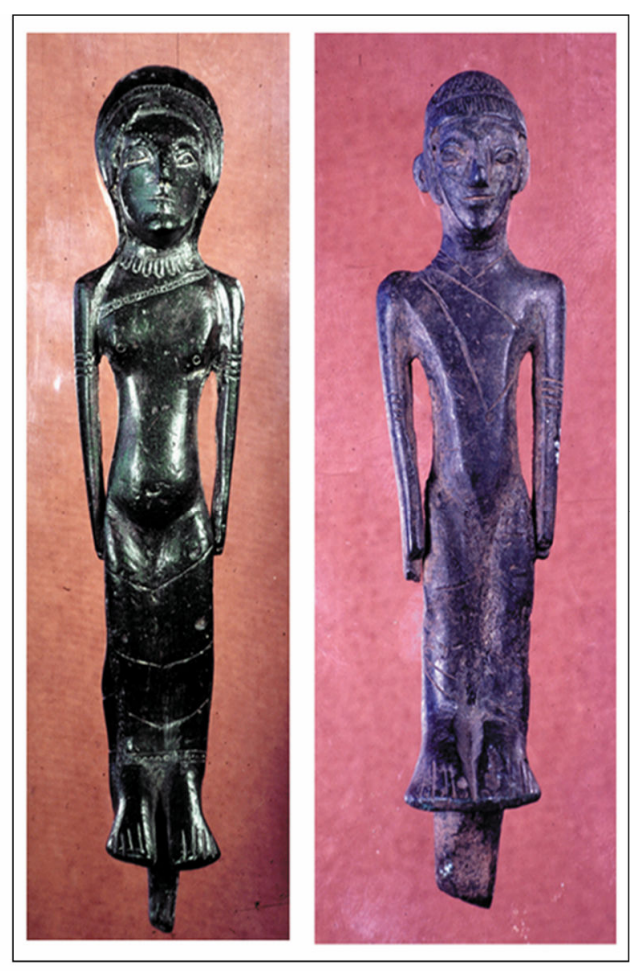

B

Figura 3. A) Exvoto de la Cueva de La Lobera (Castellar), ss. III-II a.C. (MAN); B) Exvoto del Collado de los Jardines, s. III a.C. (MAN).

Los exvotos de bronce pleno, hechos a molde, propios del territorio de Cástulo (Cazlona, Linares) y, en mucha menor cuantía y periodo de vigencia, de La Luz (Santo Ángel, Verdolay), son los más característicos (Rueda, 2011; Tortosa y Camino, 2018: 247-274). Con ellos comienza el ciclo de la élite ibérica de oferentes masculinos y femeninos clasificados por edades (Prados, 1997: 273-282), con los brazaletes en espiral como distintivo más común. Las mujeres adolescentes se adornan con sus trenzas, sujetan ocasionalmente su pelo con una banda sencilla y ciñen su cintura, sin mostrar más joya específica que, eventualmente, collares simples. Los desnudos, depositados por quienes entran en la edad reproductiva, tienden a mostrar las armas que los convierten en ciudadanos. El grupo adulto masculino presenta dos variantes: los guerreros, pocas veces a caballo, con pendiente anular, brazalete y cinturones abrochados con hebillas ostentosas, y los personajes con túnica, a veces igualmente armados, mientras que las adultas se caracterizan por sus cofias cónicas, por su manto y por lucir collares; se presentan calzadas, con rodetes y collares con bulla central, en la línea de las antiguas damas (Fig. 3A). 
Un grupo del que hay apenas diez ejemplares de ambos sexos, debe corresponder a oferentes de un origen distinto al de la mayoría (Fig. 3B). Destaca sobre todos los demás por la finura de su ejecución, que no es local. Son personajes con espiga bajo los pies descalzos para ser fijados a una peana ${ }^{3}$, con peinados diferentes al conjunto ibérico, con exclusivas vestimentas transparentes y mantos oblicuos rematados por cenefas, a los que suman los tradicionales collares, aunque aquí con colgantes tipo Aliseda, y los brazaletes en espiral (Prados, 1992: núms. 182 a 187 y 630-631; Rueda, 2012, inv. núms. 185 y 194).

Hay que señalar, por último, que a lo largo del siglo II a.C., según el testimonio de los pequeños bronces, los ritos de paso decrecen a favor del incremento de representaciones de fecundidad a las que se añaden exvotos anatómicos que rebajan la exclusividad social propia de la fase inicial.

Este es el panorama perceptible también a través de muchos de los exvotos de terracota ibéricos. El santuario de La Serreta (Alcoi, Cocentaina, Penàguila) (Grau et al., 2017: 61-118) es interesante para observar a través de las 434 piezas inventariadas, en primer lugar, la pérdida del referente de Aliseda en las cabezas contestanas, con toca, corona a modo de stephané (en sustitución de la diadema), rodetes y collar ibéri$\cos , \mathrm{y}$, en segundo lugar, la desaparición de las joyas en las imágenes del cuidado infantil, que se invoca en un santuario donde, probablemente, se elevaban también otras súplicas (Caroll, 2019: 1-45). En el grupo de la maternidad se confirma que los hijos reemplazan las alhajas en el lenguaje iconográfico.

Es evidente que los pequeños exvotos se democratizan en el Ibérico Tardío, cuando se adaptan a las prácticas de los llamados cultos populares, destinados a la recuperación de la salud y a propiciar la continuidad de las familias (Harris, 2016), prerrogativas compartidas por la población sin distinción de clases. Como caso extremo de simplificación del mensaje, se presenta un tipo nuevo en el que un cuerpo ambiguo masculino y femenino, de estética rudimentaria, coloca los brazos sobre el seno o el vientre en clara alusión a la procreación. Ya no hay convergencia de los dos sexos sino un sincretismo elemental representado en piedra y en terracota, que nunca muestra joyas.

En paralelo, otros antropomorfos de caliza tardíos de factura simple (siglos I a.C.I d.C.) atestiguan una ritualidad residual, generalmente en lugares con una arquitectura sacra de tipologías púnica o, sobre todo, romano-republicana, a la que se debe la aparición del templo en Iberia. Los exvotos menores de Torreparedones (Castro del Río-

\footnotetext{
${ }^{3}$ Para estos bronces Nicolini propuso una cronología orientalizante que hoy no se confirma. La cultura ibérica incorpora el árula de piedra como base de exvotos con espiga de bronce por contacto con Roma, después de la Segunda Guerra Púnica (218-202 a.C.) (Montón, 1996). En los santuarios ibéricos no se conservan peanas en las que fijar exvotos con espigas.
} 
Baena), Bujalance y La Rambla (ambos en Córdoba), La Encarnación, etc., son toscos, aunque conservan algún arma como atributo, a veces un manípulo y, con más frecuencia, muestran la tira cruzada bajo el cuello y el pendiente anular masculinos, y el collar de las oferentes, estantes o excepcionalmente sedentes, que recuerdan los antiguos grupos de edad ibéricos en una época de cambio.

Cambio porque, coetáneamente, vuelve a haber talleres de buen arte que esculpen relieves y estatuas exentas destinados a edificios hispano-romanos, con evocaciones artísticas de los guerreros y oferentes ibéricos, que quedan fuera del objetivo del presente artículo (Aranegui, 2020: 155-165).

\subsubsection{El Cerro de los Santos}

Con una historia de la investigación lastrada por las falsificaciones que, finalmente, Mélida (1906) y Fernández Avilés (1962: 62-74) lograron esclarecer ante la opinión internacional, el segundo santuario ibérico (Lantier, 1917) dado a conocer al gran público y el que ha proporcionado más piezas escultóricas, bien labradas en caliza y de gran formato, que cualquiera de los yacimientos ibéricos, continúa estando hoy rodeado de incertidumbres, pese a los avances de la investigación (Ruiz, 1989; Noguera, 1998: 150152; Blánquez y Polak, 2016: 477-505). Se trata de un ejemplo sin par, con todo lo que ello conlleva, con exvotos muy potentes en comparación con los de bronce y terracota, pero de cronología imprecisa, porque la contextualización arqueológica de las esculturas brilla por su ausencia. El yacimiento ha proporcionado algún fragmento tanto de cerámica ática como de terra sigillata y se admite que tuvo una fase ibérica seguida de una etapa floreciente romano-republicana, aunque el transcurso de los siglos comprendidos entre el IV a.C. y el I d.C. ha carecido de contextos estratigráficos hasta fechas recientes (Ruiz, 1985: 394-402; García Cardiel, 2015: 85-104). Se encuentra en la estación viaria romana de Ad Palem $^{4}$ (Jiménez Cobo, 2001: 101-151), donde un templo in antis fue erigido hacia el siglo I a.C. (Brotóns y Ramallo, 2017: 93-116), el cual, en consonancia con la tradición ibérica, no tiene atribuida ninguna imagen de culto, ni lápida votiva.

A continuación, abriré mis observaciones a debate, con las cautelas con que lo han hecho otros autores.

Mi hipótesis de partida reside en plantear El Cerro de los Santos propiamente dicho -con esculturas- como un santuario federal asociado a una vía pecuaria bajo custodia de una organización política de más alcance que un oppidum, tal vez una mancomunidad

\footnotetext{
${ }^{4}$ Pale es una diosa romana menor, protectora de la naturaleza, del ganado y de los pastores, que sugiere el carácter trashumante de la vía.
} 
inclusiva, abierta a negotiatores y publicani (Marín, 1988; Aranegui, 2012: 158-163). A la vista de lo más conocido de este santuario, su iconografía, sorprende, en primer lugar, la desaparición del guerrero en la tipología escultórica, de lo que puede deducirse la garantía de la paz. Y, a otros efectos, también es significativo observar un cierto número de representaciones exentas femeninas, unas de más de un metro de altura y otras menores, en buen estado de conservación (MAN 3500, 3508, 3513, 7632. Dama sedente del Museo de Albacete), con la parte posterior apenas esbozada que reposan sobre una base o plinto similar. Este tratamiento es propio de esculturas que cumplen su función adosadas a una pared, posiblemente en un espacio cubierto al que confieren identidad. Todas van calzadas y, salvo la imagen sedente, ofrecen el vaso caliciforme (Fig. 4A), poco frecuente en los bronces votivos (Izquierdo, 2002: 9-29), si bien pieza característica de muchas cuevas-santuario de áreas sin apenas exvotos antropomorfos (Gil-Mascarell, 1975: 281-332), aunque presente en los materiales del Cerro y con espléndidos ejemplares de plata en los tesoros de Tivissa (Castellet de Banyoles) (Serra Ràfols, 1941: 15-33) y de Salvacañete (Cuenca) (Cabré, 1936: 151-160).

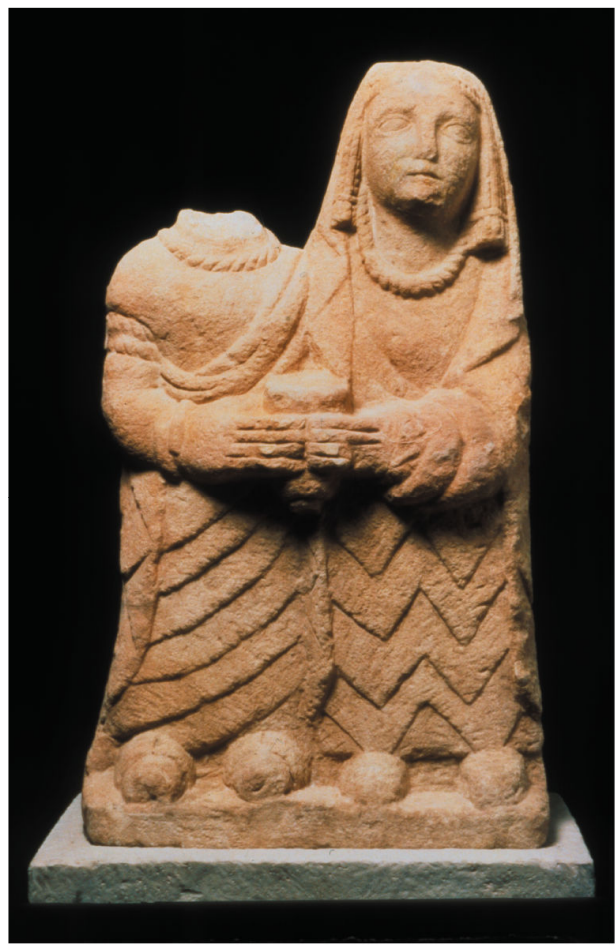

A

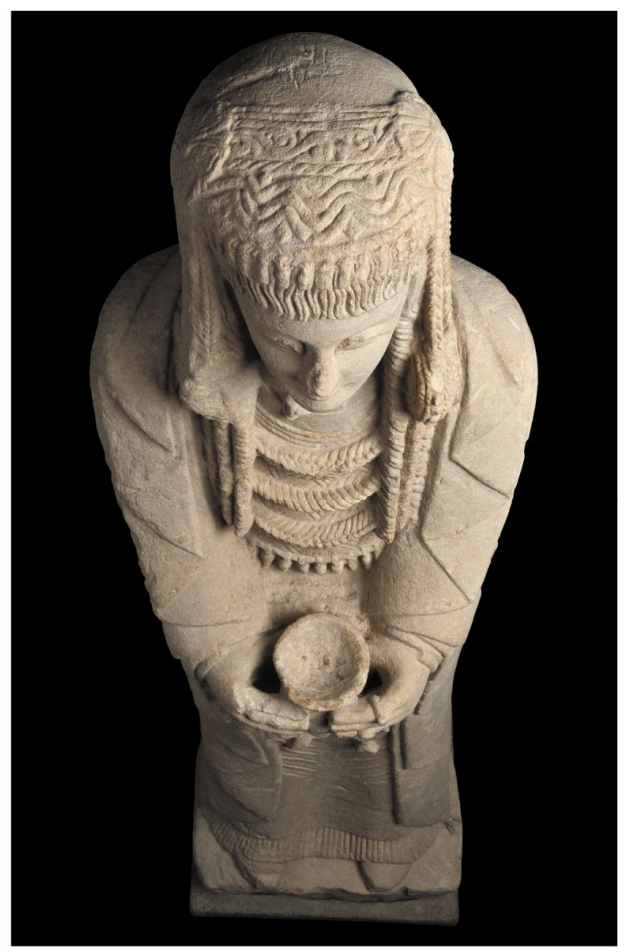

B

Figura 4. A) Pareja de oferentes del Cerro de los Santos, s. II-I a.C. (MAN);

B) "Gran Oferente" del Cerro de los Santos, ss. II-I a.C. (MAN). 
El testimonio de los devotos propiamente dichos hay que buscarlo en los demás personajes, bustos, cabezas, togados..., expuestos temporalmente y amortizados periódicamente en favissae habilitadas constructivamente en el recinto sacro (Sánchez, 2002: 269-270), como es habitual y como sugiere la relativa dispersión de la concentración de hallazgos, así como su recuperación más dañada. El tercer punto de interés se orienta hacia algunos exvotos masculinos y el total de los femeninos que permanecen al margen de la vestimenta romana, aunque llegan a convivir con ella. Son piezas que ratifican que la tradición ibérica se mantuvo, fundamentalmente, en femenino. En estos términos, la introducción de la toga masculina, que se ha datado en el siglo II a.C. (García Cardiel, 2019: 155-179), no tiene por qué separarse de las oferentes (alrededor de un tercio del total de las esculturas), artífices, una vez eliminada la belicosidad ibérica, de la confluencia cultural con Roma. Y, en consecuencia, habría que reconsiderar la existencia de un templo anterior al siglo I a.C. (Brotóns y Ramallo, 2017), a la luz de los primeros templos hispanos, como el de Sagunto, y de la datación de los palliati del santuario albaceteño que controla el Corredor de Almansa, de gran interés económico, muy posiblemente relacionado con la producción textil, conocida en Roma (Plin. Nat. VIII, 191).

La Gran Oferente (MAN 3500, h. 1,35 m) (Fig. 4B) es el icono más famoso y mejor conservado de las imágenes tutelares del Cerro de los Santos, con leves restos de policromía y pasador en T para abrochar la túnica, más tardío que la fíbula anular. Salvo por la ausencia de cofia, es la escultura del Cerro que mejor representa la indumentaria ancestral, que se enriquece con una joyería en la que una diadema historiada, collares y sortijas evocan el recuerdo de las damas y, mirando más allá con nuestros ojos, reflejan el último alcance de Aliseda. Datada hacia el 150-50 a.C. (Ruiz, 1985: 398), habría que asumir esta cronología y olvidar la convencional del 300 a.C. Supone un eco que, por intermedio de las damas, llega de muy lejos, paradójicamente del extremo opuesto de la península, lo que vuelve a traer a colación aquella hipotética ruta de los santuarios, ya olvidada (Maluquer de Motes, 1987: 19-25; Domínguez Monedero, 2013: 393-405).

Concluiré esta exposición con reservas frente al criterio que deriva la protohistoria peninsular de aculturaciones pendulares, porque hay iniciativas locales que filtran lo que llega del exterior modificándolo, como muestran la tipología de la orfebrería extremeña y el arte escultórico ibérico, en el que la combinación de ciertas joyas se estandariza y significa poder. Cuando este canon pasa a la escultura, se convierte en emisario de la construcción social de una jerarquía que evoluciona desde el lenguaje masculino reverencial y guerrero al de una rica tradición productiva declinada en femenino, todavía evocada al producirse el contacto con Roma.

Godella, febrero de 2021 


\section{BIBLIOGRAFÍA}

ALBERTOCCHI, M. (2004): Athana Lindia. Le statuette siceliote con pettorali di età arcaica e classica, Roma.

ALMAGRO GORBEA, M. ${ }^{a}$ J. (1989-90): “Orígenes y desarrollo de la orfebrería ibérica. Estudio y paralelos en las Damas de Baza y de Elche”, Anales de Prehistoria y Arqueología, 5-6, pp. 115-129.

ALMAGRO GORBEA, M. (2008): “Objetos suntuarios. Joyería”, en M. Almagro Gorbea (dir.): La necrópolis de Medellín. II. Estudio de los hallazgos, Bibliotheca Praehistorica Hispana, 26 (2), Madrid, pp. 371-400.

ARANEGUI, C. (1996): "Signos de rango en la sociedad ibérica. Distintivos de carácter civil o religioso", Revista de Estudios Ibéricos, 2, pp. 91-121.

(2008): "La prevalencia de representaciones femeninas: el caso de la cultura ibérica", en L. Prados y C. Ruiz (eds.), pp. 205-224.

(2010): "El lenguaje del prestigio: a propósito de la Dama de Baza", en T. Chapa e I. Izquierdo (coords.): La Dama de Baza. Un viaje femenino al Más Allá, Madrid, pp. 185-194.

(2012): Los iberos ayer y hoy. Arqueologías y culturas, Madrid.

(2015): “Ocultaciones de objetos de valor", en C. Aranegui (ed.): El sucronensis sinus en época ibérica, Saguntum-PLAV, Extra-17, Valencia, pp. 158-176.

(2018): La Dama de Elche, dónde, cuándo y por qué, Madrid.

(2020): "Estrategias identitarias. El arte como paradigma en la Hispania tardo-republicana, J. M.

Noguera, I. López y L. Baena (eds.): Satyrica signa. Estudios de arqueología clásica en homenaje al profesor Pedro Rodríguez Oliva, Granada, pp. 155-165.

BELÉN, M. ' (2009): "Phoenicians in Tartessos”, en M. Dietler y C. López-Ruiz (eds.): Colonial Encounters in Ancient Iberia: Phoenician, Greek and Indigenous Relations, Chicago, pp. 193-228.

(2012): "Mujeres en las necrópolis tartesias", en L. Prados (ed.), C. López y J. Parra (coords.): La arqueología funeraria desde una perspectiva de género, Madrid, pp. 179-200.

BERROCAL, L. (1989): "Placas áureas de la Edad del Hierro en la Meseta occidental", Trabajos de Prehistoria, 46, pp. 279-291.

BLÁNQUEZ, J. y POLAK, G. (2016): "Nuevos documentos para el estudio del santuario ibérico del Cerro de los Santos en el legado monumental de Augusto Fernández Avilés del CeDAP de la UAM", en B. Gamo y R. Sanz (coords.): Actas de la I Reunión cientifica de Arqueología de Albacete, Albacete, pp. 477-505.

BROTONS, F. y RAMALLO, S. F. (2017): “Continuidades y cambios en los santuarios ibéricos del sureste de Iberia: los templos in antis del Cerro de los Santos y del cerro de la Ermita de La Encarnación", en T. Tortosa y S. F. Ramallo (eds.): El tiempo final de los santuarios ibéricos en los procesos de impacto y consolidación del mundo romano, Anejos AEspA, 79, Madrid, pp. 93-116. 
CABRÉ, J. (1936): “El Tesoro de Salvacañete (Cuenca)”, Archivo Español de Arqueología, 12, 35, pp. 151-160.

CAMPOS, J. M. (2019): "Panorama actual de la arqueología urbana en Huelva”, Bienes, paisajes e itinerarios/ revista PH, 96, pp. 46-57.

CAROLL, M. (2019): “Mater Matuta. 'Fertility Cults' and the Integration of Women in Religious Life in Italy in the Fourth to First Centuries BC", Papers of the British School at Rome, 87, pp. 1-45.

CELESTINO, S. (2000) (ed.): El yacimiento protohistórico de Pajares. Villanueva de la Vera, Cáceres, 1. Las necrópolis y el tesoro áureo, Memorias de Arqueología Extremeña, 3, Mérida. (2001): Estelas de guerrero y estelas diademadas: la precolonización y formación del mundo tartésico, Barcelona.

CELESTINO, S. y BLANCO, J. L. (2006): La joyería en los orígenes de Extremadura: El espejo de los dioses, Ataecina, 01, Badajoz.

CELESTINO, S. y JIMÉNEZ, J. (eds.). (2005): El Periodo Orientalizante. Actas del III Simposio Internacional de Arqueología de Mérida: Protohistoria del Mediterráneo Occidental, Anejos de AEspA, XXXV, Mérida.

CHERIF, Z. (1987): "Les bijoux carthaginois d'après les figurines en terre cuite", Reppal III, pp. $117-150$.

DOMÍNGUEZ MONEDERO, A. (2013): “La aportación de Joan Maluquer de Motes al conocimiento de la presencia griega en la Península Ibérica”, Revista d'Arqueologia de Ponent, 23, pp. 393-405.

ESCACENA, J. L. y AMORES, F. (2011): "Revestidos como dios manda. El tesoro del Carambolo como ajuar de consagración”, Spal, 20, pp. 107-141.

FERNÁNDEZ DE AVILÉS, A. (1962): "Escultura del Cerro de los Santos. Colección del Museo de Albacete", Publicaciones del Seminario de Historia y Arqueología de Albacete, Albacete, pp. 62-74.

FRONTISI-DUCROUX, F. y LISSARRAGUE, F. (1998): “Signe, objet, support: regard privé, regard public", Ktéma, pp. 137-143.

GARCÍA CARDIEL, J. (2015): "El Cerro de los Santos: paisaje, negociación social y ritualidad entre el mundo ibérico y el hispano”, Archivo Español de Arqueología, 88, pp. 85-104.

(2019): "Revestir el poder en tiempos de cambio: el uso de la toga entre las elites ibéricas (ss. III a.C.)", Archivo Español de Arqueología, 92, pp. 155-171.

GARCÍA GANDÍA, J. R. (2009): La necrópolis orientalizante de Les Casetes (La Vila Joiosa), Alicante.

GIL-MASCARELL, M. (1975): “Sobre las cuevas ibéricas del País Valenciano. Materiales y problemas", Papeles del Laboratorio de Arqueología de Valencia, 11, pp. 281-332.

GONZÁlEZ, J. (1987): Escultura ibérica del Cerrillo Blanco, Porcuna, Jaén, Diputación Provincial, Jaén. 
GRAU, I., AMORÓS, I. y LÓPEZ-BERTRAN, M. (2017): "La colección de terracotas", en I. Grau et al. (cols.): El santuario ibérico y romano de La Serreta (Alcoi, Cocentaina, Penàguila). Prácticas rituales y paisaje en el área central de la Contestania, Alcoi, pp. 61118.

HARRIS, W.V. (ed.). (2016): Popular Medicine in Greco-Roman Antiquity, Brill, Leiden.

HERNÁNDEZ, M. (2017): “Los tesoros de Villena”, en A. Rodríguez Díaz, I. Pavón y D. Duque (eds.): Historia de Tesoros, Tesoros con Historia, Cáceres, pp. 37-60.

HORN, F. (2011): Ibères, Grecs et Puniques en Extrême-Occident. Les terres cuites de l'espace ibérique du VIIIe au IIe siècles av. J.-C. BCV, 54, Madrid.

HUEZEY, L. A. (1897): Comptes rendus de l'Académie des Inscriptions et Belles-Lettres, 41 (5), pp. 505-509.

IZQUIERDO, I. (1998): “La imagen femenina del poder. Reflexiones en torno a la feminización del ritual funerario en la cultura ibérica", Actas del congreso internacional Los Iberos, Príncipes de Occidente, Saguntum-PLAV, Extra-1, Valencia, pp. 185-193.

(2002): "Exvotos ibéricos, moldes y copias. A propósito de un conjunto femenino de oferentes de bronce”, Boletín del Museo Arqueológico Nacional, 20, pp. 9-29.

(2008): "Gestualidad, imagen y género: exvotos femeninos del santuario ibérico del Cerro de los Santos (Montealegre del Castillo, Albacete)”, en L. Prados y C. Ruiz (eds.), pp. 251-296.

JIMÉNEZ COBO, M. (2001): “La vía romana 'Castulo-Saetabis' ”, Boletín del Instituto de Estudios Giennenses, 179, pp. 101-151.

KASSAB, D., DE FENOYL, A., BALLET, P. y BESQUES, S. (1985): “Cinquante ans de découvertes et de travaux sur les figurines de terre cuite grecques et romaines", Revue Archéologique, 1, pp. 77-114.

LANTIER, R. (1917): El Santuario Ibérico de Castellar de Santisteban, Memorias del Centro de Investigaciones Paleontológicas y Prehistóricas, 15, Madrid.

MACHUCA, F. (2017): “Cultos, ritos y santuarios fenicios en la Ulterior-Baetica: una aproximación a su dimensión identitaria", X Coloquio del Centro de Estudios Fenicios y Púnicos, Cádiz-San Fernando, poster online.

MALUQUER DE MOTES, J. (1987): “Comercio continental focense en la Extremadura central”, Ceràmiques gregues $i$ helenístiques en la península ibèrica, Barcelona, pp. 19-25.

MARÍN CEBALLOS, Ma . C. y BELÉN, M. (2002-2003): "En torno a una dama entronizada de Torreparedones", Homenaje a E. Ruano. Boletín de la Asociación de Amigos de la Arqueología, 45, pp. 177-194.

MARÍN DÍAZ, M. a A. (1988): Emigración, colonización y municipalización en la Hispania republicana, Universidad de Granada, Granada.

MARTÍN, J. A. y FERNÁNDEZ RECHE, S. (2007): "La orfebrería procedente de las necrópolis fenicas de Malaca", Spal, 16, pp. 187-194.

MÉLIDA, J. R. (1906): Las esculturas del Cerro de los Santos: cuestión de autenticidad, Revista de Archivos, Bibliotecas y Museos, Madrid. 
MONTÓN, F. J. (1996): Las árulas de Tárraco, Tarragona.

NAVARRO, A. y SAN MARTÍN, C. (2018): "Oro para los dioses. Nuevas perspectivas para la caracterización técnica e iconográfica del Carambolo", en A. Navarro y E. Ferrer (coords.): Trabajo sagrado. Producción y representación en el Mediterráneo occidental durante el I milenio a.C., Spal Monografías, 25, Sevilla, pp. 157-181.

NICOLINI, G. (1990): Techniques des ors antiques. La bijouterie ibérique du VII au IV siècle, Picard, París.

NOGUERA, J. M. (1998): “El Cerro de los Santos”, Catálogo de la Exposición Los Iberos Príncipes de Occidente, Lunwerg, Barcelona, pp. 150-152.

OLIVER, A. y PEREA, P. (1999): "El depósito ritual del Puig de la Nau (Benicarló, Castellón), Quaderns de Prehistòria i Arqueologia de Castelló, 20, pp. 198-208.

PARIS, P. (1906): "Le trésor de Javea (Espagne)", Revue Archéologique, 7, pp. 424-435.

PEREA, A. (1996): "La orfebrería peninsular en el marco del arcaísmo mediterráneo: dos perspectivas", en R. Olmos y P. Rouillard (eds.): Formas arcaicas y arte ibérico, Madrid, pp. 95110.

(1997): "El busto en piedra aparecido hace un siglo en La Alcudia", en R. Olmos y T. Tortosa (eds.): La Dama de Elche. Lecturas desde la diversidad, Madrid, pp. 145-157.

(2000): “Comportamientos de mercado en la producción orfebre del taller de Cádiz”, Intercambio y comercio preclásico en el Mediterráneo, Madrid, pp. 281-292.

(2006): "Entre metáfora y mito. La representación simbólica de lo femenino en la sociedad ibérica", MARQ arqueología y museos, 01, pp. 49-68.

(2018): "Contacts and Transitions: Iron Ager Gold in Eastern Iberian Peninsula", en R. Schwab, P.-Y. Milcent, B. Armbruster y E. Pernicka (eds.): Early Iron Age Gold in Celtic Europe, Leidorf, Rahden/Westf., pp. 357-368.

PEREA, A. y ARMBRUSTER, B. (2011): “Tomb 100 at Cabezo Lucero: New Light on Goldworking in Fourth-Century BC Iberia", Antiquity, 85, pp. 158-171.

PEREA, A. y OLMOS, R. (2018): “El poder en sus manos”, L. Prados, C. Rueda y A. Ruiz (eds.), pp. 535-566.

PRADOS, L. (1992): Exvotos ibéricos de bronce del Museo Arqueológico Nacional, Madrid. (1997): "Los ritos de paso y su reflejo en la toréutica ibérica", en R. Olmos y J. A. Santos (eds.): Iconografia ibérica, iconografia itálica. Propuesta de interpretación y lectura, Madrid, pp. 273-282.

PRADOS, L., RUEDA, C. y RUIZ, A. (eds.), Bronces ibéricos. Una historia por contar. Libro homenaje al Prof. Gérard Nicolini, Madrid.

PRADOS, L. y RUIZ, C. (eds.). (2008): Arqueología del género, Madrid.

QUILLARD, B. (2013): Bijoux carthaginois III: les colliers. Apports de trois décenies, De Boccard, París.

RENFREW, C. y MORLEY, I. (2007): Image and Imagination. A Global Prehistory of Figurative Representation, Cambridge. 
RÍSQUEZ, C. y RUEDA, C. (eds). (2013): Santuarios iberos: territorio, ritualidad y memoria, Actas del congreso 'El santuario de la Lobera de Castellar (Jaén)', Torredonjimeno.

RODRÍGUEZ ARIZA, M. a O., GÓMEZ, F. y MONTES, E. (2008): “El túmulo 20 de la necrópolis ibérica de Tútugi (Galera, Granada)", Trabajos de Prehistoria, 65 (1), pp. 169-180.

RODRÍGUEZ DÍAZ, A., PAVÓN, I. y DUQUE, D. (2019): El Tesoro de Aliseda, cien años después. En el laberinto de sus historias, Barcelona.

RUEDA, C. (2011): Territorio, culto e iconografia en los santuarios iberos del Alto Guadalquivir (ss. IV a.n.e-I d.n.e.), Jaén.

(2012): Exvotos ibéricos, núm. 2. El Instituto Gómez-Moreno. Fundación Rodríguez-Acosta (Granada), Jaén.

RUIZ, M. (1985): "Últimas aportaciones a la cronología del Cerro de los Santos", Congreso de Historia de Castilla-La Mancha, Ciudad Real, pp. 395-402.

(1989): Los exvotos del santuario del Cerro de los Santos, Albacete.

SAN NICOLÁS, M. P. (1987): Las terracotas figuradas de la Ibiza púnica, Consiglio Nazionale delle Ricerche, Roma.

SÁNCHEZ GÓMEZ, M. ${ }^{a}$ L. (2002): El santuario de El Cerro de los Santos (Montealegre del Castillo, Albacete): nuevas aportaciones arqueológicas, Albacete.

SANTOS, M. a J. (2009): “Estelas diademadas: revisión de criterios de clasificación”, Herakleion, 9, pp. 7-40.

SERRA, J. de C. (1941): "El Tesoro de Tivissa”, Ampurias, 3, pp. 15-33.

TORELLI, M. (1997): Il rango, il rito e l'immagine: alle origini della rappresentazione storica romana, Milán.

TORRES, M. (2011): “La 'dama de Cádiz'”, “La 'dama de Villaricos' ”, en M. Almagro Gorbea y M. Torres (coords.): La escultura fenicia en España, Madrid, pp. 49-56 y 273-278.

TORTOSA, T. y COMINO, A. (2018): "Los exvotos del Santuario de La Luz (Santo Ángel, Murcia) como elementos de comunicación religiosa”, en L. Prados, C. Rueda y A. Ruiz (eds.), pp. 247-274.

UROZ, H. (2006): El programa religioso iconográfico de la 'tumba del orfebre' de Cabezo Lucero (Guardamar del Segura, Alicante), Monografía del Museo de Arte Ibérico de El Cigarralejo, 3, Murcia.

WULFF, F. (2009): “¿Por qué las identidades hoy? Historia antigua y Arqueología ante un cambio de paradigma", en F. Wulff y M. Álvarez Martí-Aguilar (eds.): Identidades, culturas y territorios en la Andalucía prerromana, Málaga, pp. 11-50.

Carmen ARANEGUI GASCÓ http://orcid.org/0000-0002-3398-833X

Carmen.Aranegui@uv.es 